\title{
Phase III randomised controlled trial of neoadjuvant chemotherapy plus radical surgery vs radical surgery alone for stages IB2, IIA2, and IIB cervical cancer: a Japan Clinical Oncology Group trial (JCOG 0102)
}

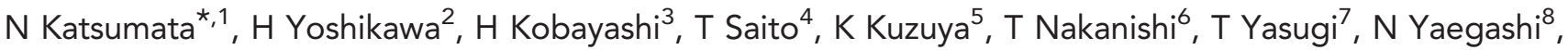
H Yokota ${ }^{9}$, S Kodama ${ }^{10}$, T Mizunoe $^{11}$, M Hiura ${ }^{12}$, T Kasamatsu ${ }^{13}$, T Shibata $^{14}$ and T Kamura ${ }^{15}$ on behalf of the Japan Clinical Oncology Group

${ }^{1}$ Department of Medical Oncology, Nippon Medical School Musashikosugi Hospital, Kawasaki, Japan; ${ }^{2}$ Department of Obstetrics and Gynecology, University of Tsukuba, Tsukuba, Japan; ${ }^{3}$ Department of Obstetrics and Gynecology, Kyushu University, Fukuoka, Japan; ${ }^{4}$ Department of Gynecologic Oncology, Kyushu Cancer Center, Fukuoka, Japan; ${ }^{5}$ Kuzuya Clinic, Nagoya, Japan; ${ }^{6}$ Department of Gynecologic Oncology, Aichi Cancer Center, Nagoya, Japan; ${ }^{7}$ Department of Obstetrics and Gynecology, Tokyo University, Tokyo, Japan; ${ }^{8}$ Department of Obstetrics and Gynecology, Tohoku University, Sendai, Japan; ${ }^{9}$ Department of Gynecologic Oncology, Saitama Cancer Center, Saitama, Japan; ${ }^{10}$ Department of Gynecologic Oncology, Niigata Cancer Center, Niigata, Japan; ${ }^{11}$ Department of Gynecologic Oncology, Kure Medical Center, Kure, Japan; ${ }^{12}$ Department of Gynecologic Oncology, Shikoku Cancer Center, Matsuyama, Japan; ${ }^{13}$ Department of Gynecologic Oncology, National Cancer Center Hospital, Tokyo, Japan; ${ }^{14} J a p a n$ Clinical Oncology Group Data Center, Multi-institutional Clinical Trial Support Center, National Cancer Center, Tokyo, Japan and ${ }^{15}$ Department of Obstetrics and Gynecology, Kurume University, Kurume, Japan

Background: A phase III trial was conducted to determine whether neoadjuvant chemotherapy (NACT) before radical surgery (RS) improves overall survival.

Methods: Patients with stage IB2, IIA2, or IIB squamous cell carcinoma of the uterine cervix were randomly assigned to receive either BOMP (bleomycin $7 \mathrm{mg}$ days $1-5$, vincristine $0.7 \mathrm{mg} \mathrm{m}^{-2}$ day 5 , mitomycin $7 \mathrm{mg} \mathrm{m}^{-2}$ day 5 , cisplatin $14 \mathrm{mg} \mathrm{m}^{-2}$ days $1-5$, every 3 weeks for 2 to 4 cycles) plus RS (NACT group) or RS alone (RS group). Patients with pathological high-risk factors received postoperative radiotherapy (RT). The primary end point was overall survival.

Results: A total of 134 patients were randomly assigned to treatment. This study was prematurely terminated at the first planned interim analysis because overall survival in the NACT group was inferior to that in the RS group. Patients who received postoperative RT were significantly lower in the NACT group (58\%) than in the RS group (80\%; $P=0.015)$. The 5 -year overall survival was $70.0 \%$ in the NACT group and $74.4 \%$ in the RS group $(P=0.85)$.

Conclusion: Neoadjuvant chemotherapy with BOMP regimen before RS did not improve overall survival, but reduced the number of patients who received postoperative RT.

${ }^{\star}$ Correspondence: Dr N Katsumata; E-mail: nkatsuma@nms.ac.jp

This study was presented in abstract form at the Annual Meeting of the American Society of Clinical Oncology, June 2006 and June 2010.

Received 30 November 2012; revised 17 March 2013; accepted 1 April 2013; published online 2 May 2013

(c) 2013 Cancer Research UK. All rights reserved 0007-0920/13 
Treatment of International Federation of Gynaecology and Obstetrics (FIGO) stages IB2, IIA2, and IIB cervical cancer remains controversial. Bulky stage IIA (tumour diameter $>4 \mathrm{~cm}$ ) cervical cancer was revised to stage IIA2 (Pecorelli et al, 2009) in the FIGO staging system in 2009. Major treatment options include radical surgery (RS) with or without postoperative radiotherapy (RT), neoadjuvant chemotherapy (NACT) followed by RS with or without postoperative RT, and concurrent chemoradiotherapy (CCRT). Radical surgery usually entails type III radical hysterectomy (Piver et al, 1974) plus pelvic or para-aortic lymphadenectomy (or both). For stage IB2 and IIA2 cervical cancer, the National Comprehensive Cancer Network (NCCN Clinical Practice Guidelines, 2012) clinical guidelines mainly recommend CCRT (category 1) and, to a lesser degree, radical hysterectomy with pelvic lymphadenectomy and para-aortic lymph node sampling (category 2b). In Japan, however, more radical procedures, such as Okabayashi's (type III or IV) radical hysterectomy plus pelvic or para-aortic lymphadenectomy (or both), remain the standard treatment of choice for stages IB2, IIA2, and IIB cervical cancer (Fujii et al, 2007).

Before we started this study, only one randomised controlled trial conducted at a single centre had compared NACT plus RS with RS alone. In 1997, Sardi et al (1997) reported the results of a randomised trial that compared NACT plus RS with RS in 205 patients with stages IB squamous cell cervical cancer. Three courses of NACT with vincristine, bleomycin, and cisplatin (VBP) were given in NACT group. Overall survival at 8 years with NACT group was superior to RS group ( $81 \%$ vs $66 \%, P<0.05)$. In a subgroup analysis in patients with non-bulky tumours $<4 \mathrm{~cm}$, there was no significant difference between the two groups ( $82 \%$ vs $77 \%$, NS).

Thus, NACT plus RS has emerged as a valid alternative investigational treatment. In 1998, one institution affiliated with our group confirmed that combination chemotherapy with bleomycin, vincristine, mitomycin, and cisplatin (BOMP) produced a high response rate $(76 \%)$ in metastatic cervical cancer (Shimizu et al, 1998). We decided to use the BOMP regimen as NACT.

To clarify the potential benefits of NACT before RS, we undertook a phase III, randomised controlled trial to compare NACT plus RS with RS alone in patients with stages IB2, IIA2, and IIB cervical cancer.

\section{PATIENTS AND METHODS}

Eligibility criteria. Patients who had primary, previously untreated, histologically confirmed squamous cell carcinoma of the cervix with bulky FIGO stage IB2, IIA, and IIB disease (tumour diameter $>4 \mathrm{~cm}$ on magnetic resonance imaging (MRI)) were eligible for this Japan Clinical Oncology Group (JCOG) study (JCOG 0102). In July 2003, the criteria were amended to patients with FIGO stage IB2, IIA2 (tumour diameter $>4 \mathrm{~cm}$ by clinical measurement), and IIB (irrespective of tumour diameter) disease and additionally required the presence of target cervical lesions $(>2 \mathrm{~cm}$ ) on MRI according to the Response Evaluation Criteria in Solid Tumours (RECIST) guidelines. Patients who were suitable candidates for radical hysterectomy as described in the treatment schedule section were eligible. Patients were also required to be between 20 and 70 years of age, to have performance status of 0 or 1 , and to have normal organ functions and normal electrocardiogram. Patients with any of the following conditions were excluded: synchronous or metachronous (within 5 years) malignancy other than carcinoma in situ or mucosal cancer; pregnancy; psychotic disease; active infection with fever; uncontrolled hypertension or diabetes mellitus; positive hepatitis B surface antigen; a history of heart failure, unstable angina, or myocardial infarction; interstitial pneumonitis or pulmonary fibrosis; or severe obesity, liver cirrhosis, or bleeding tendency. All patients gave informed consent before enrolment in this study, which was approved by the institutional review boards at the participating institutions (UMINCTR No. C000000194 and clinicaltrials.gov No. NCT00190528).

\section{Treatment schedule}

Neoadjuvant chemotherapy. Patients were randomly assigned to receive either NACT followed by RS or RS alone. The BOMP regimen for NACT comprised bleomycin $(7 \mathrm{mg})$ as a 30 -min intravenous infusion on days $1-5$, vincristine $\left(0.7 \mathrm{mg} \mathrm{m}^{-2}\right)$ as a bolus intravenous injection on day 5 , mitomycin $\left(7 \mathrm{mg} \mathrm{m}^{-2}\right)$ as a bolus intravenous injection on day 5 , and cisplatin $\left(14 \mathrm{mg} \mathrm{m}^{-2}\right)$ as a 30-min intravenous infusion on days $1-5$ of a 21-day cycle. Patients initially received two cycles. Patients who had a complete response $(\mathrm{CR})$ or partial response $(\mathrm{PR})$ after two cycles of BOMP were given two additional cycles. Treatment was administered if the white cell count was $\geqslant 2000$ per $\mu \mathrm{l}$ and the platelet count was $\geqslant 75000$ per $\mu$ l. Treatment could be delayed for up to 2 weeks until these minimum criteria were met.

After NACT, the patients were clinically reassessed and classified as suitable or unsuitable for radical hysterectomy. The criteria for radical hysterectomy includes adequate organ function with good performance status. The unsuitable patients received RT, including whole pelvis RT and brachytherapy.

Surgery. The standard procedure used to perform radical hysterectomy in this study was based on Okabayashi's radical hysterectomy as reported by Kyoto Imperial University in 1921. This procedure involves wide extirpation of the parametrial tissue and separation of the posterior leaf of the vesicouterine ligament (Okabayashi, 1921). With the use of this technique, the surgeon can separate the bladder with the ureter completely away from the lateral side of the cervix and the vagina. This dissection facilitates resection of all periureteral tissue and any length (more than one-third) of the vagina and paravaginal tissues. Okabayashi's radical hysterectomy is thus classified as type III or IV radical hysterectomy (Okabayashi, 1921).

In this study, radical hysterectomy require removal of at least $3 \mathrm{~cm}$ of the vaginal and paravaginal tissues, and if the vagina was involved, removal of the vagina and vaginal tissues with a margin of at least $2 \mathrm{~cm}$ from the cancer. Twenty or more pelvic lymph nodes were required to dissect. If metastases to the para-aortic nodes were suspected, the para-aortic nodes were sampled or dissected. Radical surgery was performed within 3 weeks after randomisation in the RS group and within 8 weeks after the last administration of chemotherapy in the NACT group.

Postoperative RT. The protocol required that postoperative RT was started within 6 weeks after surgery. A total dose of 4500 5040 cGy was delivered to the whole pelvis in daily fractions of 180200 cGy if patients had pelvic lymph node metastasis, parametrial involvement, or deep stromal invasion $(\geqslant 2 / 3)$. Extended-field external beam therapy, delivering a dose of 4500 cGy by a four-field technique, was administered to patients with positive para-aortic nodes. High-dose rate brachytherapy was delivered to the vaginal stump if patients had positive surgical margins.

Response and toxicity evaluation. Tumour response in the NAC group was assessed according to the RECIST guidelines (Therasse et al, 2000). Target lesions, including the primary cervical tumour, were measured by MRI. An independent response review committee evaluated all tumour responses after the investigators had completed their assessments.

Toxicities were evaluated according to the National Cancer Institute Common Toxicity Criteria (NCI-CTC, version 2.0) (Trotti et al, 2000). Surgical morbidity was defined as adverse events related to surgery that occurred between the date of surgery 
1 month postoperatively. Early and late adverse events of RT were respectively defined as adverse events that occurred within the first 90 days or more than 90 days after the completion of RT. Late adverse events were evaluated according to the RTOG/EORTC Late Radiation Morbidity Scoring Scheme in Appendix IV of NCICTC, version 2.0 (Trotti et al, 2000).

Statistical considerations. This was a randomised, multicentre, nonblinded, prospective, phase III study. After confirmation of the inclusion/exclusion criteria by telephone or fax to the JCOG Data Center, the patients were randomly assigned to treatment according to a minimisation procedure. Minimisation criteria were disease stage (I; II), age ( $\leqslant 50$ years; $>50$ years), and institution. The primary end point was overall survival. The secondary end points were progression-free survival, surgical morbidity, compliance with radical hysterectomy, omission of postoperative irradiation, early and late radiation-related morbidity, and rate of response to chemotherapy. Overall survival was measured from the date of registration to the date of death from any cause, and data were censored at the time of the last follow-up for surviving patients. Progression-free survival was measured from the date of randomisation to the date of the first event (i.e., confirmation of disease progression or death from any cause), and data were censored at the last date on which the absence of disease progression was confirmed.

We assumed that the 5 -year survival rate would be $60 \%$ in the RS group and $75 \%$ in the NACT group. The planned sample size was 100 patients in each treatment group, with a one-sided $\alpha$-level of 0.05 , a power of 0.8 , an accrual of 5.5 years, and a follow-up of 3.5 years (Schoenfeld and Richter, 1982). Two interim analyses were scheduled. The first interim analysis was done when 100 patients had been randomly assigned to treatment, and the second was done when all patients had been assigned treatment. Multiplicity was adjusted by the method proposed by the Southwest Oncology Group (Green et al, 1997). The significant levels were one-sided 0.005 at each interim analysis and one-sided 0.045 at the final analysis. Survival curves were estimated with the Kaplan-Meier method, and stratified log-rank tests were used to assess differences between treatment groups, stratified according to disease stage (I $v s$ II) and age ( $\leqslant 50$ years $v s>50$ years). We used a Cox proportional hazard model to estimate treatment effects. All analyses were done on an intention-to-treat basis, except for toxicity. Toxicity analyses were restricted to patients who had received at any part of their assigned treatment. Although this trial was designed for one-sided hypothesis testing, follow-up results are reported with two-sided $P$-values because of the exploratory nature of the analysis. All analyses were carried out using SAS software, version 9.1 (SAS Institute, Cary, NC, USA).

\section{RESULTS}

Enrolment in this study began on 1 December 2001. The first planned interim analysis was performed in July 2005 (Figure 1). Data from 108 patients enrolled by November 2004 were analysed. On the basis of this analysis, the Data and Safety Monitoring Committee (DSMC) recommended to prematurely terminate the study because overall survival in the NACT group was inferior to that in the RS group (HR, 2.11; multiplicity-adjusted 99\% CI, $0.34-13.2$ ), and the predicted probability of significant superiority in the NACT group at the end of the study as assessed by Spiegelhalter's method (Spiegelhalter et al, 1993) was extremely low (6.4\%). The study was therefore closed on 1 August 2005.

Between December 2001 and August 2005, a total of 134 patients (67 in the NACT group and 67 in the RS group) were randomly assigned to treatment at 28 institutions. Table 1 summarises the baseline characteristics of the patients. One patient

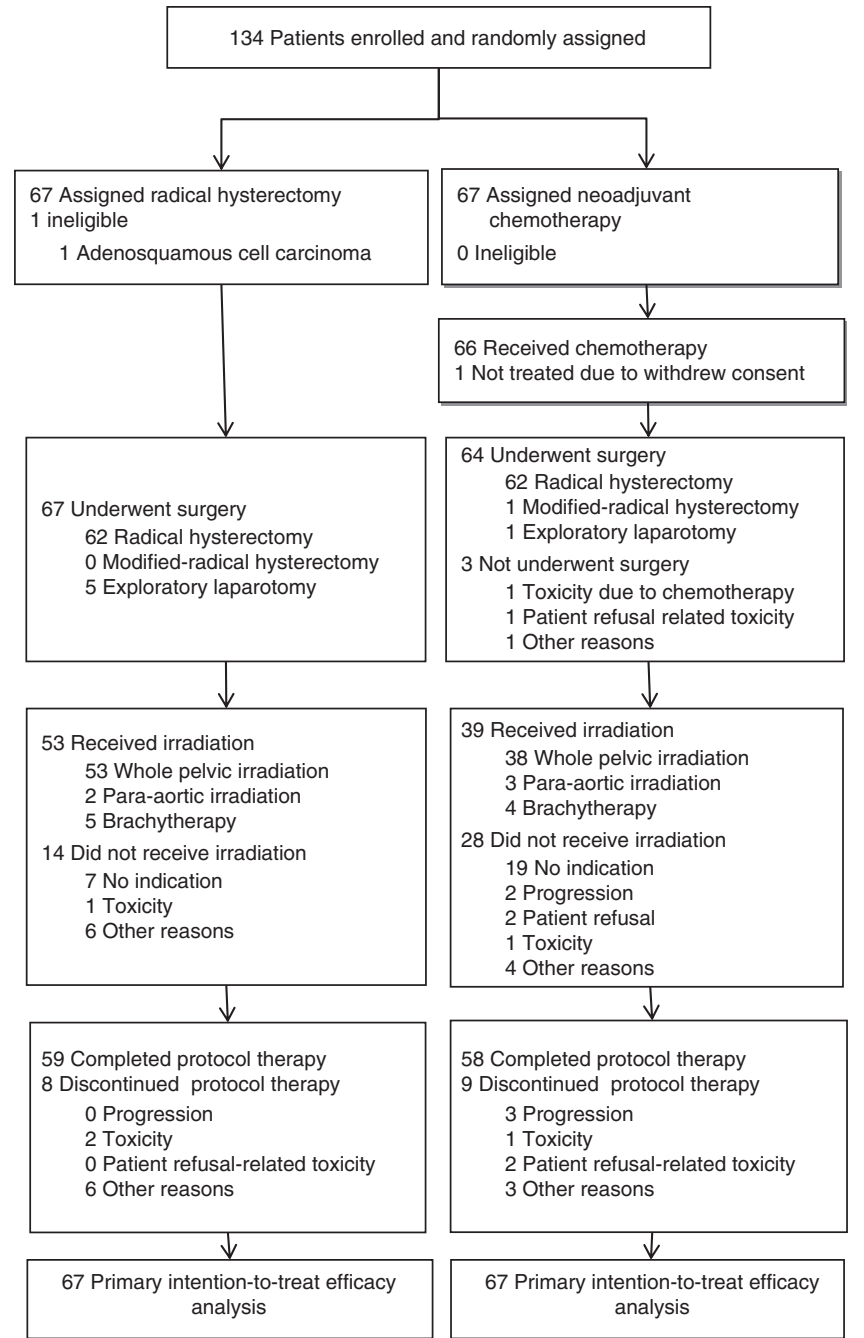

Figure 1. Trial profile.

in the RS group was ineligible because of an incorrect histopathological diagnosis of adenosquamous carcinoma on cervical biopsy before enrolment. Three patients in the NACT group who were given a diagnosis of squamous cell carcinoma on biopsy before enrolment were found to have adenosquamous carcinoma on evaluation of their surgical specimens. These patients were considered eligible.

Of the 67 patients randomly assigned to the NACT group, 66 received chemotherapy. One patient did not receive chemotherapy because of her refusal after registration. This patient underwent primary RS. The other 66 patients received at least two cycles of NACT. The overall response $(\mathrm{CR}+\mathrm{PR})$ rate was $70 \%$ (47 out of 67 ) on the investigators' assessment and 66\% (44 out of 67) on independent central review (Table 2). Toxicity associated with chemotherapy is summarised in Table 3. Nearly all toxic effects were tolerable, and chemotherapy could be continued in all but three patients who discontinued treatment during the third or fourth cycle because of toxicity (persistent grade 3 thrombocytopenia in two patients and grade 3 skin toxicity in one patient). Grade 3 alkalosis with hypertension, thrombosis, atrial fibrillation, or skin ulceration occurred in one patient each, but these toxic effects were transient and soon resolved.

Of the 67 patients in each group, 62 (93\%) underwent RS, suggesting that operability was similar in the groups. Five patients in the RS group and one in the NACT group underwent laparotomy for RS, but the procedure was terminated during surgery because of inoperable disease associated with conditions 
Table 1. Patient characteristics

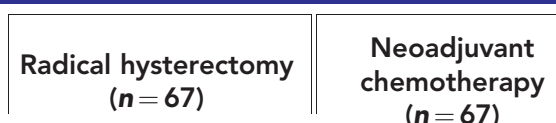

$(n=67)$

$(n=67)$

\begin{tabular}{|c|c|c|c|c|}
\hline & $\begin{array}{c}\text { No. of } \\
\text { patients }\end{array}$ & $\%$ & $\begin{array}{c}\text { No. of } \\
\text { patients }\end{array}$ & $\%$ \\
\hline \multicolumn{5}{|c|}{ Age, years } \\
\hline $\begin{array}{l}\text { Median } \\
\text { Range }\end{array}$ & \multicolumn{2}{|c|}{$\begin{array}{c}46 \\
22-67\end{array}$} & \multicolumn{2}{|c|}{47} \\
\hline
\end{tabular}

ECOG performance status

\begin{tabular}{|l|c|c|c|c|}
\hline 0 & 59 & 88 & 62 & 93 \\
\hline 1 & 8 & 12 & 5 & 8 \\
\hline
\end{tabular}

\section{FIGO stage}

\begin{tabular}{|l|c|c|c|c|}
\hline IB2 & 26 & 39 & 24 & 36 \\
\hline IIA & 7 & 10 & 5 & 8 \\
\hline IIB & 34 & 51 & 38 & 57 \\
\hline
\end{tabular}

\section{Histology in biopsy}

\begin{tabular}{|l|c|c|c|c|}
\hline Squamous cell & 66 & 99 & 67 & 100 \\
\hline Adenosquamous cell & 1 & 1 & 0 & 0 \\
\hline
\end{tabular}

Abbreviations: $\mathrm{ECOG}=$ Eastern Cooperative Oncology Group; $\mathrm{FIGO}=$ International Federation of Gynaecology and Obstetrics surgical staging system.

Table 2. Clinical response of neoadjuvant chemotherapy

\begin{tabular}{|c|c|c|}
\hline Response category & $\begin{array}{l}\text { Investigator } \\
\text { assessment } \\
(n=67)\end{array}$ & $\begin{array}{l}\text { Independent } \\
\text { central review } \\
\quad(n=67)\end{array}$ \\
\hline CR & $9(13)$ & $8(12)$ \\
\hline PR & $38(57)$ & $36(54)$ \\
\hline SD & 18 (27) & 20 (30) \\
\hline PD & $0(0)$ & $0(0)$ \\
\hline NE & 1 (1) & 2 (3) \\
\hline Overall response & $47(70)$ & $44(66)$ \\
\hline $95 \% \mathrm{Cl}$ & $58-81$ & $53-77$ \\
\hline \multicolumn{3}{|c|}{$\begin{array}{l}\text { Abbreviations: } \mathrm{Cl}=\text { confidence interval; } C R=\text { complete response; } N E=\text { not evaluabl } \\
P D=\text { progressive disease; } P R=\text { partial response; } S D=\text { stable disease. Values are presente } \\
\text { as } n(\%) \text {. }\end{array}$} \\
\hline
\end{tabular}

such as pelvic wall involvement, disseminated tumours, or both. Median dissected lymph nodes were 47 (range 20-119) in the RS group and 45 (range 13-95) in the NACT group. Para-aortic lymph node sampling and dissection were respectively performed in 22 and 14 patients in the RS group and 20 and 14 patients in the NACT group. Median blood loss and operation time were respectively $950 \mathrm{ml}$ and $5.5 \mathrm{~h}$ in the RS group and $1370 \mathrm{ml}$ and $5.6 \mathrm{~h}$ in the NACT group.

Table 4 shows the pathological findings of surgical specimens obtained from patients who underwent RS. The median tumour diameter in the NACT group was smaller than that in the RS group $(3.0 v s 5.1 \mathrm{~cm})$. On postsurgical T classification (pT), downstaging to pT0-Ib1 was confirmed in $40 \%$ of the patients in the NACT
Table 3. Toxicity of chemotherapy $(n=66)$

\begin{tabular}{|l|c|c|c|}
\hline & Grade 3 & Grade 4 & Grade 3 or 4 (\%) \\
\hline Leukopenia & 24 & 3 & 41 \\
\hline Neutropenia & 21 & 15 & 56 \\
\hline Haemoglobin & 11 & 5 & 24 \\
\hline Thrombocytopenia & 18 & 0 & 27 \\
\hline Hyponatraemia & 3 & 0 & 5 \\
\hline Hyperkalaemia & 1 & 0 & 2 \\
\hline Nausea & 11 & - & 17 \\
\hline Vomiting & 4 & 0 & 6 \\
\hline Febrile neutropenia & 2 & 0 & 3 \\
\hline Fatigue & 3 & 0 & 5 \\
\hline Hypersensitivity & 2 & 0 & 3 \\
\hline
\end{tabular}

Table 4. Surgical findings

Radical hysterectomy $(n=62)$

Neoadjuvant chemotherapy

$(n=62)$

\begin{tabular}{|c|c|c|c|c|}
\hline & $\begin{array}{l}\text { No. of } \\
\text { patients }\end{array}$ & $\%$ & $\begin{array}{l}\text { No. of } \\
\text { patients }\end{array}$ & $\%$ \\
\hline \multicolumn{5}{|c|}{ Tumour diameter $(\mathrm{cm})$} \\
\hline $\begin{array}{l}\text { Median } \\
\text { Range }\end{array}$ & \multicolumn{2}{|c|}{$\begin{array}{c}5.1 \\
2.5-13.5\end{array}$} & \multicolumn{2}{|c|}{$\begin{array}{c}3 \\
0-10.3\end{array}$} \\
\hline \multicolumn{5}{|c|}{ Postsurgical T classification (pT) } \\
\hline 0-IB1 & 5 & 8 & 25 & 40 \\
\hline IB2-pT2B & 57 & 92 & 34 & 55 \\
\hline$>2 \mathrm{~B}$ & 0 & 0 & 3 & 5 \\
\hline Positive pelvic nodes & 27 & 44 & 17 & 27 \\
\hline $\begin{array}{l}\text { Invasion to muscle } \\
\text { layer } \geqslant 2 / 3\end{array}$ & 52 & 84 & 38 & 61 \\
\hline Parametrial invasion & 28 & 45 & 25 & 40 \\
\hline
\end{tabular}

group. The proportion of patients with positive pelvic nodes was lower but statistically not significant in the NACT group than in the RS group $(27 \%$ vs $44 \%, P=0.091)$, whereas parametrial involvement was similar in both groups ( $40 \%$ vs $45 \%, P=0.717)$. The incidence of para-aortic lymph node metastasis was 2 and 1 in the RS group and NACT group, respectively.

As for surgical morbidity, ureteral or bladder injuries occurred and were repaired during surgery in two patients in the RS group and two in the NACT group. A ureterovaginal fistula developed postoperatively in another patient in the RS group. Grade 3 wound infections occurred in one patient in the RS group and two patients in the NACT group. Grade 3 dysuria developed in one patient in the RS group. Grade 3 disseminated intravascular coagulation occurred in one patient in the NACT group. The incidences of pneumonia, bowel obstruction, and haemorrhage during the first month after surgery were similar in both treatment groups $(0,3$, and 0 patients in the RS group $v s 1,2$, and 1 patients in the NACT group).

The proportion of patients who met the criteria for postoperative radiation (i.e., lymph node metastasis, parametrial involvement, or deep stromal invasion $>2 / 3$ ) was significantly lower in the NACT group (48 (72\%) of 67$)$ than in the RS group (59 $(89 \%)$ of $66 ; P=0.015)$, and the patients who received 


\begin{tabular}{|c|c|c|c|c|c|c|}
\hline & \multicolumn{3}{|c|}{$\begin{array}{l}\text { Radical hysterectomy } \\
\qquad(n=66)\end{array}$} & \multicolumn{3}{|c|}{$\begin{array}{c}\text { Neoadjuvant } \\
\text { chemotherapy }(n=67)\end{array}$} \\
\hline & $\begin{array}{c}\text { Grade } \\
\quad 3\end{array}$ & $\begin{array}{c}\text { Grade } \\
4\end{array}$ & $\begin{array}{c}\text { Grade } \\
3 \text { or } 4 \\
(\%)\end{array}$ & $\begin{array}{c}\text { Grade } \\
3\end{array}$ & $\begin{array}{c}\text { Grade } \\
4\end{array}$ & $\begin{array}{c}\text { Grade } \\
3 \text { or } 4 \\
(\%)\end{array}$ \\
\hline \multicolumn{7}{|c|}{ Early adverse events } \\
\hline Leukocytes & 0 & 0 & 0 & 1 & 0 & 1 \\
\hline Haemoglobin & 0 & 0 & 0 & 2 & 1 & 4 \\
\hline Thrombocytes & 0 & 0 & 0 & 1 & 0 & 1 \\
\hline Diarrhoea & 5 & 0 & 8 & 2 & 0 & 3 \\
\hline Nausea & 0 & - & 0 & 1 & - & 1 \\
\hline Vomiting & 0 & 0 & 0 & 1 & 0 & 1 \\
\hline Lymphedema & 1 & 0 & 2 & 0 & 0 & 0 \\
\hline Dysuria & 1 & - & 2 & 0 & - & 0 \\
\hline $\begin{array}{l}\text { Urinary } \\
\text { retention }\end{array}$ & 9 & 0 & 14 & 5 & 0 & 7 \\
\hline \multicolumn{7}{|c|}{ Late adverse events ${ }^{a}$} \\
\hline Lymphedema & 2 & 0 & 3 & 5 & 0 & 7 \\
\hline $\begin{array}{l}\text { Urinary } \\
\text { retention }\end{array}$ & 7 & 0 & 11 & 3 & 1 & 6 \\
\hline $\begin{array}{l}\text { Vesicovaginal } \\
\text { fistula }\end{array}$ & 1 & 0 & 2 & 1 & 1 & 3 \\
\hline $\begin{array}{l}\text { Bowel } \\
\text { obstruction }\end{array}$ & 6 & 0 & 9 & 1 & 2 & 4 \\
\hline
\end{tabular}

radiation in the NACT group (39 (58\%) of 67) were lower than those in the RS group (53 (79\%) of $67 ; P=0.015)$. Postoperative $\mathrm{RT}$ to the whole pelvis, RT to the para-aortic region, and brachytherapy were respectively given to 53,2 , and 5 patients in the RS group and 38, 3, and 4 patients in the NACT group. Early adverse events (within 90 days after radiation) occurred in $70 \%$ (46 of 66 ) of the patients in the RS group and 55\% (37 of 67; $P=0.108)$ of the patients in the NACT group. Grade 3 or 4 haematologic toxicity was more common in the NACT group than in the RS group (Table 5), whereas nonhaematologic toxic effects such as diarrhoea or urinary retention were more common in the RS group than in the NACT group. Late adverse events (90 days or more after radiation) occurred in 65\% (43 of 66) of the patients in the RS group and $42 \%$ ( 28 of $67 ; P=0.009$ ) of the patients in the NACT group. The incidence of grade 3 or 4 lymphedema was slightly higher in the NACT group than in the RS group, whereas urinary retention and bowel obstruction were more common in the RS group than in the NACT group. One patient in the NACT group died of perforation and necrosis of the small intestine 215 days after the last dose of radiation. This death was considered treatment related.

At the time of final follow-up (May 2008), with a median follow-up of 49 months for patients with censored data, there had been 17 deaths in the NACT group and 16 in the RS group. The 5 -year overall survival was $70.0 \%$ in the NACT group and $74.4 \%$ in the RS group (Figure 2; hazard ratio (HR) by Cox regression analysis, 1.07; 95\% CI, 0.54-2.12; two-sided $P=0.85$, stratified logrank test). The 5-year progression-free survival was $59.9 \%$ in the NACT group and $62.7 \%$ in the RS group (Figure 2; HR, 1.06; 95\% CI, $0.60-1.88$; two-sided $P=0.85$, stratified log-rank test). On subgroup analyses among patients with stage IB2 disease, the

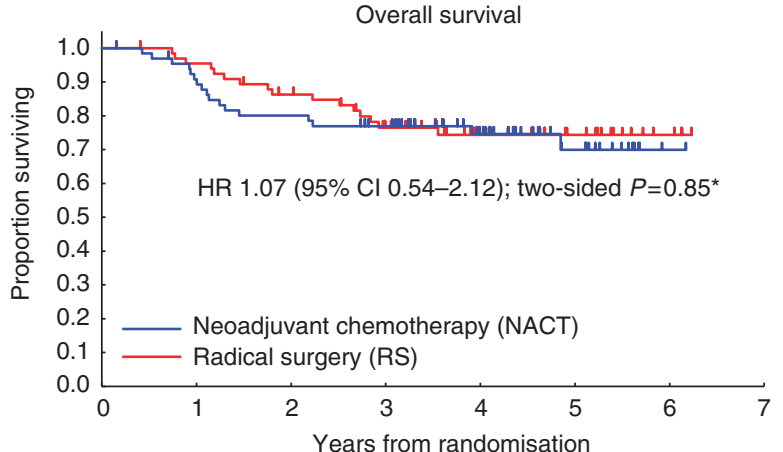

\begin{tabular}{|c|c|c|c|c|c|c|c|}
\hline \multicolumn{3}{|c|}{ Number at risk } & \multicolumn{4}{|c|}{ ( } & \\
\hline NACT & 67 & 63 & 55 & 43 & 26 & 14 & 4 \\
\hline RS & 67 & 59 & 52 & 47 & 30 & 14 & 1 \\
\hline
\end{tabular}

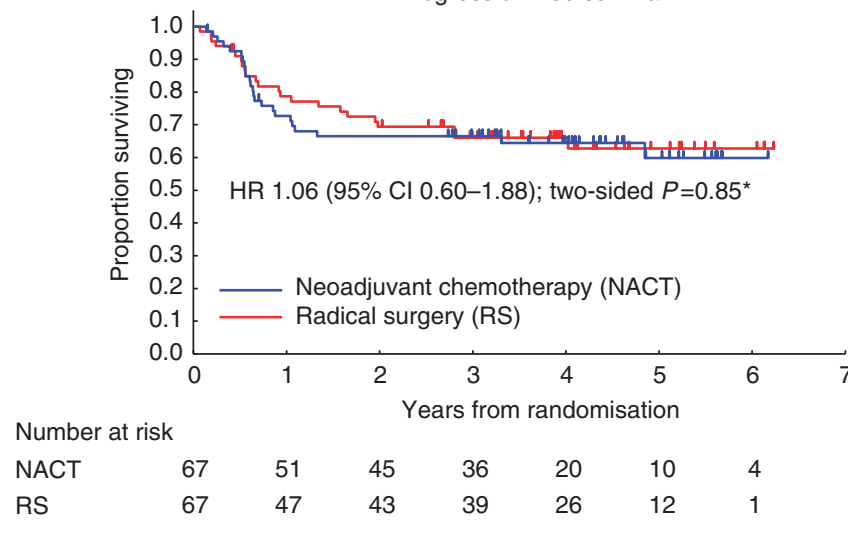

*Stratified Cox regression analysis and stratified log-rank test

Figure 2. Survival curves of all randomised patients.

5-year overall survival and progression-free survival were, respectively, $82.9 \%$ and $71.2 \%$ in the RS group $(n=25)$ and $78.4 \%$ and $60.5 \%$ in the NACT group $(n=25)$, and among patients with stages IIA2 and IIB disease, the 5-year overall survival and progression-free survival were $69.5 \%$ and $58.4 \%$ in the RS group $(n=42)$ and $65.3 \%$ and $59.3 \%$ in the NACT group $(n=42)$.

\section{DISCUSSION}

Our study concluded that NACT with BOMP before RS did not improve overall survival of patients with stages IB2, IIA2, and IIB cervical cancer. However, NACT was associated with a reduced proportion of patients who received postoperative RT.

The benefits of NACT followed by surgery as compared with surgery alone were addressed in a Cochrane meta-analysis (Rydzewska et al, 2010) of six phase III trials (FIGO stage of the subjects: Sardi's trial (Sardi et al, 1997), IB1 + IB2; Napolitano's trial (Napolitano et al, 2003), IB-IIIB; Cai's trial (Cai et al, 2006), IB1 + IB2; Katsumata's trial (present study) (Katsumata et al, 2006), IB2, IIA2, IIB; Eddy's trial (Eddy et al, 2007), IB2; Chen's trial (Chen et al, 2008), IB2-IIB) of 1036 patients, including our immature survival data, after a median follow-up of 34 months. Progression-free survival was significantly improved by NACT + $\mathrm{RS}(\mathrm{HR}=0.76,95 \% \mathrm{CI}, 0.62-0.94)$. However, the improvement in overall survival with NACT plus RS was not statistically significant $(\mathrm{HR}=0.85,95 \% \mathrm{CI}, 0.67-1.07)$. Only Sardi's trial showed a statistically significant benefit of NACT in terms of overall survival ( $\mathrm{HR}=0.53,95 \% \mathrm{CI}, 0.31-0.92)$ (Sardi et al, 1997). Among the six trials, Eddy's GOG trial (Eddy et al, 2007) and our trial 
demonstrated no survival benefit of NACT $(\mathrm{HR}=1.01,95 \% \mathrm{CI}$, $0.68-1.49$ and $\mathrm{HR}=1.12,95 \% \mathrm{CI}, 0.56-2.22$ ). Why the results differed substantially among trials remains unclear. The metaanalysis concluded that the type of drugs used or how they were given had no effect on the overall results. Moreover, the results were similar in women with early-stage disease and those with more advanced cancer.

The clinical response rate of $67 \%$ reported in this study is lower than the rate of $84 \%$ obtained in patients with stage IB2 disease in Sardi's trial (quick VBP regimen: intravenous vincristine $1 \mathrm{mg} \mathrm{m}^{-2}$, bleomycin $25 \mathrm{mg} \mathrm{m}^{-2}$ on days $1-3$ and cisplatin $50 \mathrm{mg} \mathrm{m}^{-2}$ every 10 days for 3 cycles), but higher than the rate of $52 \%$ obtained in Eddy's GOG trial (quick VP regimen, intravenous vincristine $1 \mathrm{mg} \mathrm{m}^{-2}$ and cisplatin $50 \mathrm{mg} \mathrm{m}^{-2}$ every 10 days for 3 cycles). A previous meta-analysis of Neoadjuvant Chemotherapy for Locally Advanced Cervical Cancer Meta-analysis Collaboration (2003) reported that the timing and dose intensity of cisplatinbased NACT appear to have an important impact on the benefits of such treatment despite some unexplained heterogeneity between the trials in their design and results.

It is very difficult to compare the radicality of RS among trials in the Cochrane meta-analysis. Two of the trials (Napolitano's and Sardi's trials) reported markedly increased rates of radical resection with NACT, whereas no difference was found in the three trials (Cai's, Chen's, and Eddy's trials). In the present study, the rate of RS was similar in NACT group and RS group (93\%). The 5-year survival rate of patients with stage IB2 disease in the RS group of Sardi's trial was only $60 \%$, whereas the 4 -year survival rate of patients with stage IB2 disease in the RS group of our study was $82 \%$. Perhaps more radical surgery eliminates the survival benefits of NACT.

Concurrent chemoradiotherapy has been considered as current standard adjuvant therapy after RS for patients with high-risk factors for recurrence since 2000 (Peters et al, 2000). The role of NACT for high-risk patients who will receive chemoradiotherapy after RS is unclear. Radiotherapy alone was administered in previous NACT trials including our study. Therefore, concurrent chemoradiotherapy should be included when conducting the future NACT trial.

Optimal regimens for NACT have yet to be defined. Among the six trials included in the Cochrane meta-analysis, four trials used cisplatin-based chemotherapy combined with vincristine, three trials used bleomycin, and two trials used 5-fluorouracil or mitomycin because these trials were started between 1987 and 2001. Cisplatinbased chemotherapy combined with ifosphamide, paclitaxel, and topotecan may be more effective for cervical cancer (Omura et al, 1997; Moore et al, 2004; Long et al, 2005). Paclitaxel combined with cisplatin was associated with a higher response rate and better progression-free survival in patients with metastatic cervical cancer (Moore et al, 2004), and one phase III trial reported that a combination of paclitaxel, cisplatin, and ifosphamide had a significantly higher response rate than cisplatin and ifosphamide (Buda et al, 2005). To clarify the benefits of neoadjuvant chemotherapy, more potent regimens of chemotherapy should be explored.

In this study, the proportion of patients who received postoperative RT was significantly lower in the NACT group than in the RS group (58\% vs 80\%). In Eddy's GOG trial, the rate of postoperative RT was small, but not significantly lower in the NACT group than in the RS group (45\% vs 52\%). When we compared improvements in extrauterine pathological findings associated with NACT between these studies, the reduction in the proportion of patients with positive pelvic nodes was more apparent in the present study than in the GOG trial (from $44 \%$ to $29 \%$ vs from $39 \%$ to $32 \%$ ). Improvements in other extrauterine pathological findings such as positive para-aortic nodes, parametrial involvement, and positive surgical margins were marginal in both studies. The decreased incidence of positive pelvic nodes in our trial most likely influenced the rate of postoperative RT in the NACT group.

Recently, Matsumura et al (2010) reported that NACT followed by surgery plus postoperative chemotherapy with cisplatin/ irnotecan or nedaplatin/irinotecan, but not RT, is a viable option for the treatment of stage IB2-IIB cervical cancer. This treatment offers the advantage of eliminating radiation-induced morbidity

In conclusion, NACT before RS did not improve overall survival in patients with stages IB2, IIA2, and IIB locally advanced cervical cancer. However, NACT did reduce the proportion of patients who received postoperative RT. Further trials are warranted to clarify the potential benefits of NACT in locally advanced cervical cancer, once new drugs or new combination regimens are shown to be effective as NACT, postoperative adjuvant chemotherapy, or both. Two ongoing randomised phase III trials (EORTC 55994; NCT00193739) are comparing NACT followed by surgery with concurrent chemoradiation. The results of these trials may play an important role in determining whether NACT before surgery is a valid alternative to chemoradiation.

\section{ACKNOWLEDGEMENTS}

We are indebted to Dr Naoki Ishizuka for the study design, Mr Takashi Asakawa for statistical support, Ms Mika Hiroo and Ms Harumi Kaba for data management, and Dr Haruhiko Fukuda for oversight of the study. This study was supported in part by the National Cancer Center Research and Development Fund (23-A-16 and 23-A-17) and by the Grants-in-Aid for Cancer Research (14S-1, 14S-4, 17S-1, 17S-5, 20S-1, 20S-6, 10-12, 14-12) from the Ministry of Health, Labour and Welfare, Japan.

\section{REFERENCES}

Buda A, Fossati R, Colombo N, Fei F, Floriani I, Gueli Alletti D, Katsaros D, Landoni F, Lissoni A, Malzoni C, Sartori E, Scollo P, Torri V, Zola P, Mangioni C (2005) Randomized trial of neoadjuvant chemotherapy comparing paclitaxel, ifosfamide, and cisplatin with ifosfamide and cisplatin followed by radical surgery in patients with locally advanced squamous cell cervical carcinoma: the SNAP01 (Studio Neo-Adjuvante Portio) Italian Collaborative Study. J Clin Oncol 23(18): 4137-4145.

Cai HB, Chen HZ, Yin HH (2006) Randomized study of preoperative chemotherapy versus primary surgery for stage IB cervical cancer. J Obstet Gynaecol Res 32(3): 315-323.

Chen H, Liang C, Zhang L, Huang S, Wu X (2008) Clinical efficacy of modified preoperative neoadjuvant chemotherapy in the treatment of locally advanced (stage IB2 to IIB) cervical cancer: randomized study. Gynecol Oncol 110(3): 308-315.

Eddy GL, Bundy BN, Creasman WT, Spirtos NM, Mannel RS, Hannigan E, O'Connor D (2007) Treatment of ("bulky") stage IB cervical cancer with or without neoadjuvant vincristine and cisplatin prior to radical hysterectomy and pelvic/para-aortic lymphadenectomy: a phase III trial of the gynecologic oncology group. Gynecol Oncol 106(2): 362-369.

EORTC 55994. http://www.cancer.gov/clinicaltrials/search/view?cdrid= 69375\&version=healthprofessional.

Fujii S, Takakura K, Matsumura N, Higuchi T, Yura S, Mandai M, Baba T, Yoshioka S (2007) Anatomic identification and functional outcomes of the nerve sparing Okabayashi radical hysterectomy. Gynecol Oncol 107(1): 4-13.

Green S, Benedetti J, Crowley J (1997) Interim Analysis and Data Monitoring Committee. Clinical Trials in Oncology, 1st edn, pp 80-99. Chapman \& Hall/CRC.

Katsumata N, Yoshikawa H, Hirakawa T, Saito T, Kuzuya K, Fujii T, Hiura M, Tsunematsu R, Fukuda H, Kamura T (2006) Phase III randomized trial of neoadjuvant chemotherapy (NAC) followed by radical hysterectomy (RH) versus RH for bulky stage I/II cervical cancer (JCOG 0102). Proc Am Soc Clin Oncol 24((No 18S)): abstract 5013.

Long 3rd HJ, Bundy BN, Grendys Jr EC, Benda JA, McMeekin DS, Sorosky J, Miller DS, Eaton LA, Fiorica JV (2005) Randomized phase III trial of cisplatin with or without topotecan in carcinoma of the uterine 
cervix: a Gynecologic Oncology Group Study. J Clin Oncol 23(21): 4626-4633.

Matsumura M, Takeshima N, Ota T, Omatsu K, Sakamoto K, Kawamata Y, Umayahara K, Tanaka H, Akiyama F, Takizawa K (2010) Neoadjuvant chemotherapy followed by radical hysterectomy plus postoperative chemotherapy but no radiotherapy for Stage IB2-IIB cervical canceririnotecan and platinum chemotherapy. Gynecol Oncol 119(2): 212-216.

Moore DH, Blessing JA, McQuellon RP, Thaler HT, Cella D, Benda J, Miller DS, Olt G, King S, Boggess JF, Rocereto TF (2004) Phase III study of cisplatin with or without paclitaxel in stage IVB, recurrent, or persistent squamous cell carcinoma of the cervix: a gynecologic oncology group study. J Clin Oncol 22(15): 3113-3119.

Napolitano U, Imperato F, Mossa B, Framarino ML, Marziani R, Marzetti L (2003) The role of neoadjuvant chemotherapy for squamous cell cervical cancer (Ib-IIIb): a long-term randomized trial. Eur J Gynaecol Oncol 24(1): 51-59.

NCCN Clinical Practice Guidelines (2012) Oncology-Cervical Cancer, version I. National Comprehensive Cancer Network. http://www.ncen.org/ professionals/physician_gls/pdf/cervical.pdf.

NCT00193739. http://clinicaltrials.gov/ct2/show/NCT00193739?term= NCT00193739.

Neoadjuvant Chemotherapy for Locally Advanced Cervical Cancer Metaanalysis Collaboration (2003) Neoadjuvant chemotherapy for locally advanced cervical cancer: a systematic review and meta-analysis of individual patient data from 21 randomised trials. Eur J Cancer 39(17): 2470-2486.

Okabayashi H (1921) Radical abdominal hysterectomy for cancer of the cervixuteri, modification of the Takayama operation. Surg Gynecol Obstet 33: 335-341.

Omura GA, Blessing JA, Vaccarello L, Berman ML, Clarke-Pearson DL, Mutch DG, Anderson B (1997) Randomized trial of cisplatin versus cisplatin plus mitolactol versus cisplatin plus ifosfamide in advanced squamous carcinoma of the cervix: a Gynecologic Oncology Group study. J Clin Oncol 15(1): 165-171.

Pecorelli S, Zigliani L, Odicino F (2009) Revised FIGO staging for carcinoma of the cervix. Int J Gynaecol Obstet 105(2): 107-108.

Peters 3rd WA, Liu PY, Barrett 2nd RJ, Stock RJ, Monk BJ, Berek JS, Souhami L, Grigsby P, Gordon Jr W, Alberts DS (2000) Concurrent chemotherapy and pelvic radiation therapy compared with pelvic

\section{APPENDIX}

\section{Institutions that participated in this study:}

Hokkaido University, Sapporo Medical University, Tohoku University, Tsukuba University, Gunma Prefectural Cancer Center, National Defense Medical College, Saitama Cancer Center, Saitama Medical Center, National Cancer Center Hospital, The Jikei University Hospital, The Cancer Institute Hospital, Tokyo radiation therapy alone as adjuvant therapy after radical surgery in highrisk early-stage cancer of the cervix. J Clin Oncol 18(8): 1606-1613.

Piver MS, Rutledge F, Smith JP (1974) Five classes of extended hysterectomy for women with cervical cancer. Obstet Gynecol 44(2): 265-272.

Rydzewska L, Tierney J, Vale CL, Symonds PR (2010) Neoadjuvant chemotherapy plus surgery versus surgery for cervical cancer. Cochrane Database Syst Rev (1): CD007406.

Sardi JE, Giaroli A, Sananes C, Ferreira M, Soderini A, Bermudez A, Snaidas L, Vighi S, Gomez Rueda N, di Paola G (1997) Long-term follow-up of the first randomized trial using neoadjuvant chemotherapy in stage $\mathrm{Ib}$ squamous carcinoma of the cervix: the final results. Gynecol Oncol 67(1): 61-69.

Schoenfeld DA, Richter JR (1982) Nomograms for calculating the number of patients needed for a clinical trial with survival as an endpoint. Biometrics 38(1): 163-170.

Shimizu Y, Akiyama F, Umezawa S, Ishiya T, Utsugi K, Hasumi K (1998) Combination of consecutive low-dose cisplatin with bleomycin, vincristine, and mitomycin for recurrent cervical carcinoma. J Clin Oncol 16(5): 1869-1878.

Spiegelhalter DJ, Freedman LS, Parmar MK (1993) Applying Bayesian ideas in drug development and clinical trials. Stat Med 12(15-16): 1501-1511 discussion 1513-7.

Therasse P, Arbuck SG, Eisenhauer EA, Wanders J, Kaplan RS, Rubinstein L, Verweij J, Van Glabbeke M, van Oosterom AT, Christian MC, Gwyther SG (2000) New guidelines to evaluate the response to treatment in solid tumors. European Organization for Research and Treatment of Cancer, National Cancer Institute of the United States, National Cancer Institute of Canada. J Natl Cancer Inst 92(3): 205-216.

Trotti A, Byhardt R, Stetz J, Gwede C, Corn B, Fu K, Gunderson L, McCormick B, Morrisintegral M, Rich T, Shipley W, Curran W (2000) Common toxicity criteria: version 2.0. an improved reference for grading the acute effects of cancer treatment: impact on radiotherapy. Int $J$ Radiat Oncol Biol Phys 47(1): 13-47.

This work is published under the standard license to publish agreement. After 12 months the work will become freely available and the license terms will switch to a Creative Commons AttributionNonCommercial-Share Alike 3.0 Unported License.

University, Juntendo University, Niigata Cancer Center, Nagaoka Red Cross Hospital, Shinsyu University, Aichi Cancer Center Hospital, National Hospital Organization Nagoya Medical Center, Kinki University, Osaka Medical Center for Cancer and Cardiovascular Disease, Tottori University, Kure Medical Center, Shikoku Cancer Center, National Kyushu Cancer Center, Kurume University, Kyushu University, Saga University, Kagoshima City Hospital. 